\title{
Venous thromboembolism in cancer patients: Still looking for answers (Review)
}

\author{
ROUA ANAMARIA IORGA ${ }^{1^{*}}$, OVIDIU GABRIEL BRATU ${ }^{2,3,4^{*}}$, RADU DRAGOS MARCU $^{2,4^{*}}$, \\ TRAIAN CONSTANTIN ${ }^{4,5^{*}}$, DAN LIVIU DOREL MISCHIANU ${ }^{2,3,4^{*}}$, BOGDAN SOCEA ${ }^{4,6^{*}}$, \\ MIHNEA-ALEXANDRU GAMAN $^{4 *}$ and CAMELIA CRISTINA DIACONU ${ }^{1,4^{*}}$ \\ ${ }^{1}$ Internal Medicine Department, Clinical Emergency Hospital of Bucharest, 014461 Bucharest; \\ ${ }^{2}$ Urology Department, Emergency University Central Military Hospital, 010825 Bucharest; \\ ${ }^{3}$ Academy of Romanian Scientists, 030167 Bucharest; ' University of Medicine and Pharmacy 'Carol Davila', \\ 050474 Bucharest; ${ }^{5}$ Urology Department, 'Prof. Th. Burghele' Clinical Hospital, 050652 Bucharest; \\ ${ }^{6}$ Surgery Department, ‘St. Pantelimon’ Clinical Emergency Hospital, 021659 Bucharest, Romania
}

Received July 22, 2019; Accepted August 21, 2019

DOI: $10.3892 /$ etm.2019.8019

\begin{abstract}
Patients with cancer-associated venous thromboembolism (VTE) represent a real challenge in clinical practice. Patients with cancer have a greater risk both of VTE and bleeding. There are only a few studies regarding the therapeutic approach of VTE in patients with cancer, especially after cancer surgery, and on thromboprophylaxis during chemotherapy. Many of the anticoagulation therapy recommendations for cancer patients are extrapolated from trials that are not conducted in cancer cohorts. It is essential to assess the efficacy and safety of VTE prophylaxis in this particular subgroup, which bears higher risks both of VTE recurrence and major hemorrhagic events. The introduction of direct oral anticoagulants in everyday practice represented a major evolution of the anticoagulant treatment. Direct anticoagulants could represent a more appealing alternative to low-molecular-weight heparin in paraneoplastic venous thrombosis, due to the patient comfort, easy administration of the drug and emerging studies that prove similar efficacy and safety as the standard treatment. However, there is limited data on the treatment with direct oral anticoagulants in patients with paraneoplastic venous thromboembolism.
\end{abstract}

Correspondence to: Professor Ovidiu Gabriel Bratu, Urology Department, Emergency University Central Military Hospital, 88 Mircea Vulcanescu Str, 010825 Bucharest, Romania

E-mail: ovi78doc@yahoo.com

${ }^{*}$ Contributed equally

Key words: venous thromboembolism, paraneoplastic, cancer, heparin, direct oral anticoagulants

\section{Contents}

1. Introduction

2. Risk factors for venous thromboembolism

3. Epidemiology

4. Pathophysiology of VTE in cancer

5. Treatment and secondary prevention options

6. Thromboprophylaxis

7. Special categories

8. Future treatments

9. Conclusions

\section{Introduction}

Venous thromboembolism (VTE) is a term describing deep vein thrombosis and/or pulmonary embolism (PE) and even superficial vein thrombosis and splanchnic vein thrombosis. Malignancy is well-known to be associated with venous thromboembolism, because of the hypercoagulable state induced by malignancy. VTE is the second leading cause of death in patients suffering from malignant tumors, after death from cancer itself.

Thrombotic events in cancer patients can manifest as migratory superficial thrombophlebitis, very well known as Trousseau's syndrome, deep venous thrombosis, nonbacterial thrombotic endocarditis (marantic endocarditis), disseminated intravascular coagulation, thrombotic microangiopathy, such as thrombotic thrombocytopenic purpura, and arterial thrombosis (1).

Many of anticoagulation therapy recommendations for cancer patients are extrapolated from trials that are not conducted in cancer cohorts. It is essential to assess the efficacy and safety of VTE prophylaxis in this particular subgroup, which bears higher risks of VTE recurrence and major hemorrhagic events (2).

\section{Risk factors for venous thromboembolism}

A cancer patient can have multiple well-known risk factors for a hypercoagulable state, such as prolonged immobilization, 
infections, surgery, chemotherapy, cancers with a high risk of VTE, and previous VTE or PE (3). Patient-related risk factors also include comorbidities such as chronic heart failure, acute infectious diseases, and obesity, especially in patients older than 75 years (4). A significant risk factor that creates the premise of thrombosis is the presence of central venous catheters (5).

Some of the medications used for treating cancer can also increase the risk of developing VTE, such as antiangiogenic therapies, erythropoiesis-stimulating agents, platinum-derived agents such as cisplatin, l-asparaginase, hormonal therapies and thalidomide (6).

Untreated deep vein thrombosis has a $50 \%$ risk to determine PE within three months from the onset, with a $25 \%$ mortality risk (3). Also, PE has a greater risk of recurrence in cancer patients than in non-cancer patients (7).

The relationship between the time of cancer diagnosis and VTE development was studied in a Danish retrospective study. A total of $44 \%$ of patients who had cancer at the time of VTE had distant metastasis, with a 1 -year survival rate of $12 \%$. Patients that had VTE one year before the cancer diagnosis had a slightly increased risk of distant metastasis at the time of diagnosis (8).

\section{Epidemiology}

The prevalence of clinical VTE in cancer patients is $15 \%$ and is associated with poor outcomes, with a six-fold decreased survival rate, compared with cancer patients without VTE (9), particularly in older patients, with a myeloproliferative type of cancer and patients with a late diagnosis, such as pancreatic cancer. This type of malignant tumor has a high risk of thrombosis, both arterial (3\%) and venous (10\%) (10-12). The annual incidence of VTE is 1-2/1,000 individuals in the general population, but in patients with cancer, it is 6.5-fold higher (13).

The most common cancer sites diagnosed during a VTE episode were established by a large Danish retrospective study where in the first place was pulmonary cancer (17\%), followed by pancreatic cancer $(10 \%)$, colon and rectal cancer $(8 \%)$, renal cancer (8\%) and prostatic cancer (7\%) (8). However, the VTE incidence in previously diagnosed patients was the highest in pancreatic cancer $(8.1 \%)$, kidney $(5.6 \%)$, ovary $(5.6 \%)$, lung $(5.1 \%)$ and stomach cancer $(4.9 \%)$, the lowest being associated with bladder cancer $(14,15)$. In clinical practice, it is more common to find patients with prostate, breast and lung cancer with VTE than patients with pancreatic cancer and VTE, due to the incidence of these types of cancers (16).

In a population-based cohort study, the incidence of paraneoplastic thromboembolism was the highest in older patients and in males. The study included 6,592 active cancer-associated VTEs, with a total of 112,738 cancer-associated person-years of observation. The incidence rate of first VTE in patients with active cancer was 5.8 (95\% CI 5.7-6.0) per 100 person-years. A total of 591 patients presented first VTE recurrence, with an overall incidence rate for recurrence of 9.6 (95\% CI 8.8-10.4) per 100 person-years. There was significant mortality $(64.5 \%$ after one year and $88.1 \%$ after 10 years) (16).

\section{Pathophysiology of VTE in cancer}

Several mechanisms have been proposed for pathogenesis of the hypercoagulable state, such as tumor production of tissue factor-like procoagulant and cancer procoagulant (a calcium-dependent cysteine protease), alongside with procoagulant activities expressed by host tissues (P-selectin found in platelet granules and in Weibel-Palade bodies of endothelial cells, tissue factor produced by monocytes, increased platelet activation secondary to amplified production of thrombin, neoplastic cell ADP production and high levels of von Willebrand factor, neutrophil extracellular traps) (17).

\section{Treatment and secondary prevention options}

Low molecular weight heparins $(L M W H)$. The first-line treatment of venous thrombosis in cancer patients is represented by LMWH, while unfractioned heparin (UFH) is recommended for patients with renal dysfunction. Fondaparinux and direct oral anticoagulants (DOACs) for initial treatment of acute paraneoplastic VTE have insufficient data for the routine recommendation, some studies have revealed that fondaparinux was associated with higher rates of VTE recurrence (18). For initial and long-term treatment of VTE, LMWH represents the drug of choice, due to a large amount of data that support this recommendation, that highlights the good safety and efficacy profile. LMWH have rapid onset and offset, can be easily monitored, and extensive clinical experience have been gained. Also, few drug-drug interactions have been reported, given the fact that the cancer patient receives more medications than a non-cancer patient, such as chemotherapy for cancer and different drugs for comorbidities. Dalteparin is preferred, due to data support, and represents the first recommendation for cancer-associated VTE (19). The dalteparin dose is weight-adjusted for patients up to $90 \mathrm{~kg}$. The maximum dose is $18000 \mathrm{IU} /$ day, even if the patient weighs more than $90 \mathrm{~kg}$.

For the initial treatment of VTE and PE in cancer patients, guidelines suggest LMWH over unfractionated heparin UFH, DOACs (grade 2C) and VKA therapy (grade 2B) (19), given the fact that data are insufficient to recommend the use of DOACs or fondaparinux (20).

Several guidelines, including those of the American College of Chest Physicians (ACCP), the National Comprehensive Cancer Network (NCCN) and the American Society of Clinical Oncology (ASCO), recommend LMWH as monotherapy for 3 to 6 months in patients with cancer-associated thrombosis. The NCCN guidelines also recommend that anticoagulation should be continued indefinitely in patients with active solid cancer and in those with risk factors $(21,22)$.

One of the largest meta-analyses of 8 randomized trials including 2327 cancer patients described reduced rates of recurrent VTE with LMWH compared with warfarin (RR 0.58; 95\% CI 0.43-0.77), a benefit that followed without significant survival improvement or major bleeding events (23).

The CLOT trial (on 672 cancer patients) revealed the superior efficacy of dalteparin treatment $(200 \mathrm{IU} / \mathrm{kg}$ in the first month, followed by $125 \mathrm{IU} / \mathrm{kg}$ for 5 months) compared with vitamin $\mathrm{K}$ antagonists after initial treatment with $\mathrm{LMWH}$, in cancer patients, with no increase in major bleeding events and a substantial reduction of recurrent VTE rate observed in the dalteparin-treated group (9 versus 17\%; HR, $0.48,95 \% \mathrm{CI}$ 0.30-0.77) (24). Also, the CANTHANOX and ONCENOX trials, that compared enoxaparin with warfarin, showed the 
same efficacy, but with fewer bleeding events in the enoxaparin arm (25) or no difference at all (26).

The CATCH study, that compared tinzaparin with warfarin, showed no differences in major bleeding, overall mortality and recurrence of VTE, but a significant reduction in clinically relevant non-major bleeding was observed with tinzaparin (27). Similar rates of bleeding and mortality, with reduced rates of recurrent VTE for tinzaparin, were demonstrated in the LITE trial (28).

Disadvantages of parenteral therapy are represented by the perceived treatment administration burden, training and handling the syringe, drug-induced thrombocytopenia, weight-adjusting dosage and the limited use in renal insufficiency (29).

Vitamin K antagonists (VKAs). Warfarin is not recommended for the treatment of acute VTE in patients with active cancer. Although there is extensive clinical experience and comfort of oral administration, as well as the rapid reversal of its overdose, a statistically significant amount of data pleads for limitation of VKA use in clinical practice. Also, chemotherapy, anorexia and vomiting contribute to the downfall of oral anticoagulants, especially warfarin (30).

DOACs. DOAC as single-agent (apixaban, dabigatran) for patients with active cancer are recommended by NCCN guidelines if LMWH cannot be administered or as a first option (edoxaban, rivaroxaban). Factors that could influence the efficacy of DOACs (advanced age, weight, gender, other medication, kidney or liver dysfunction, vomiting, proximal small bowel resection, urinary or gastrointestinal lesions) are stated as relative contraindications (22). The ASCO 2014 Guideline update did not include the use of DOACs, due to limited data (20). There is a current recommendation that DOACs (edoxaban and rivaroxaban) may be used for acute VTE in cancer patients with low risk of bleeding, with data to support their use (31).

Many of the large trials compared DOACs with warfarin in the general population and their results were extrapolated to cancer patients. In the EINSTEIN (32) and RECOVER (33) studies, that compared rivaroxaban versus warfarin, respectively dabigatran versus warfarin, there was no significant difference in recurrence events or bleeding events. However, these recurrence and bleeding events were higher in cancer patients than in non-cancer patients. Similar VTE recurrence rates were reported in a large meta-analysis of 6 studies (34). Apixaban reported a significant reduction in rates of recurrent VTE and hemorrhagic events versus enoxaparin followed by warfarin (35). However, there are emerging trials (36) that compare DOACs versus LMWH with or without warfarin, given the fact that practice guidelines have scarce recommendations on the optimal time to switch to DOACs [NCT02744092, CANVAS (37), NCT03240120 for dabigatran (38), NCT03045406CARAVAGGIO - apixaban vs. dalteparin (39), NCT02581176 (40)].

Edoxaban was demonstrated to be non-inferior to dalteparin for the treatment of cancer-associated VTE in a phase III trial, now the superiority of this comparison is investigated. In this trial, the patients received $60 \mathrm{mg}$ edoxaban daily, after 5-day treatment with LMWH, compared to $200 \mathrm{IU} / \mathrm{kg}$ dalteparin administration in the first month, followed by $150 \mathrm{IU} / \mathrm{kg}$ daily (41).

The SELECT-D study, conducted on 406 patients, compared rivaroxaban (15 mg twice daily for three weeks, after that, reducing the dose to $20 \mathrm{mg}$ daily for a total of six months) with dalteparin $(200 \mathrm{IU} / \mathrm{kg}$ in the first month, then $150 \mathrm{IU} / \mathrm{kg}$ daily for 5 months) and reported a reduction of the VTE recurrence rate (4\% versus $11 \%$ ), with similar rate of major bleeding (6\% versus $4 \%$ ) (42). Bleeding events have also been assessed in phase II and III clinical trials, that compare safety and efficacy of rivaroxaban versus dalteparin [NCT03139487 PRORITY (43), NCT02746185 CASTA-DIVA (44)] and with other LMWH (NCT02583191 CONKO-011) (45).

$U F H$. A meta-analysis of 15 randomized controlled trials compared UFH with LMWH, the latter being associated with a reduction in mortality rate at three months $(\mathrm{RR} 0.66,95 \% \mathrm{Cl}$ 0.40-1.1), without an increased risk of hemorrhagic events, as compared to UFH that showed a risk difference of 17 more cases per 1000 patients. Compared with fondaparinux, there was no significant difference regarding the mortality at three months, recurrent VTE or bleeding events (46).

\section{Thromboprophylaxis}

Primary thromboprophylaxis. Regarding ambulatory patients with cancer, the ASCO Guideline recommends that only high-risk patients should receive prophylactic therapy with LMWH. Hospitalized patients with active cancer should receive anticoagulation therapy, especially during chemotherapy, either with LMWH or low-dose aspirin. For minor procedures, there is no eloquent data (20). The ACCP Guideline suggests a prophylactic dose of LMWH or UHF in outpatients with solid tumors and risk factors such as chemotherapy and immobilization (19).

For the DOACs efficacy in primary thromboprophylaxis in hospitalized patients plead the results of MAGELLAN trial, that demonstrated the superiority of rivaroxaban for 35 days over enoxaparin for 10 days, followed by placebo (47).

Secondary thromboprophylaxis - extended therapy. Anticoagulant treatment beyond the conventional 3 to 6 months is frequently used, given the fact that active malignancy represents a risk factor for VTE and VTE recurrence of 10 to $20 \%$ per year, while also taking into consideration the type and activity of cancer, burden of disease, oncologic treatment, patient choice, immobility and life expectancy (19).

However, the bleeding risk must be evaluated in the extended anticoagulant therapy, considering the fact that there are scarce data supporting the treatment with LMWH beyond 6 months, such as the DALTECAN trial (21). If necessary, ASCO guideline recommends secondary prophylaxis for long-term (beyond six months) (20). The NCCN Guideline recommends $\mathrm{LMWH}$ as the preferred agents for the first 6 months (dalteparin or enoxaparin), but also includes DOACs (rivaroxaban) if patients refuse or are poor candidates for LMWH (22).

A systematic review on 5 relevant randomized clinical trials with moderate quality of evidence for survival suggested a survival benefit of heparin treatment (UFH or LMWH) in cancer 
patients and, in particular, in patients with limited small cell lung carcinoma (48). Still, a randomized trial of fraxiparin/nadroparin administration failed to show a survival benefit in patients with advanced prostate, lung or pancreatic cancer (49).

Rivaroxaban demonstrated its effectiveness and safety for the treatment of VTE and recurrence prophylaxis in patients with active cancer, in a prospective multicenter trial (50). There are large observational studies in progress, to follow-up the recurrence of VTE in extended therapy with rivaroxaban [NCT03214172 (51), NCT02742623-COSIMO (52), NCT01989845 (53)] and apixaban for the prevention of recurrent VTE in patients with active breast, prostate or colorectal cancer [NCT03692065 API-CAT STUDY (54), NCT02585713 ADAM-VTE (55)].

A Canadian systematic review of randomized trials that compared the benefit of using anticoagulation (LMWH or fondaparinux) with no anticoagulation in VTE prophylaxis concluded that there are still unknown risks and benefits of primary anticoagulant therapy for thromboprophylaxis in cancer patients (2).

\section{Special categories}

Management of recurrent thrombosis. Additional risk factors for recurrent thrombosis were cited in the RIETE Registry of 3805 patients, as being PE at debut (OR, 1.9; 95\% CI 1.2-3.1) and a recently diagnosed cancer, less than 3 months (OR, 2.0; 95\% CI 1.5-3.6). Also, the tumor site influenced the recurrence and bleeding risk, with similar rates of these events in breast cancer (5.6 and 4.1\%, respectively) and colorectal cancer (10 and $12 \%$, respectively). Lung cancer presented a two-fold higher risk of recurrence than the rate of bleeding (27 and 11\%, respectively) whereas, prostate cancer showed recurrence half of the rate of bleeding (7 versus $13 \%$, respectively) (56).

Despite adequate anticoagulation, VTE events have a three-fold increased risk of recurrence (57) and can indicate drug failure or resistance. Predictive factors for the recurrence are the presence of high concentrations of plasmatic tissue factor ( 3 fold increased risk), venous compression by the tumor or ganglia and hepatobiliary cancer (5.5 fold increased risk) (15). The recommendations include switching to LMWH when the patients are on oral anticoagulant therapy, increasing the dose or frequency of administration of LMWH for those patients already on LMWH and introducing an inferior vena cava filter (58). Also, it is recommended to test the patient for acquired or inherited thrombophilia causes (19). The benefits of switching to a direct oral anticoagulant in this population are still unknown.

Thromboprophylaxis during chemotherapy. Chemotherapy represents a risk factor for VTE, although current clinical guidelines do not recommend routine use of thromboprophylaxis in ambulatory patients. Given the fact that included patients were not stratified by using risk scores for VTE, the benefit of parenteral anticoagulant treatment needs to be assessed.

The SAVE-ONCO trial indicated a reduced incidence of VTE in this particular category of patients, with no significant increase in major hemorrhagic events, during the administration of semuloparin, an ultra-low-molecular-weight heparin, in doses of $20 \mathrm{mg}$ daily versus placebo. Patients with advanced or metastatic cancer of the lung, colon/rectum, stomach, ovary, pancreas or bladder who were starting a new chemotherapy course were included in this trial (59).

Weight-adjusted dalteparin for 12 weeks reduced VTE incidence during gemcitabine treatment for pancreatic cancer in FRAGEM trial (60) and nadroparin in patients with advanced stage lung, breast, gastrointestinal, ovarian or head and neck cancer undergoing chemotherapy in the PROTECHT trial (61).

DOACs could be a more suitable option, thus creating the premise of many trials, which compared apixaban and rivaroxaban versus placebo in thromboprophylaxis of high-risk patients (as defined by a Khorana score of $\geq 2$ ) receiving chemotherapy [NCT02048865 (62), NCT02555878 (63)].

However, some chemotherapy agents can interfere with DOAC pharmacokinetics (rivaroxaban, apixaban), due to cytochrome P450 3A4-related drug-drug interactions, with the effects of either increasing toxicity and bleeding risk (many tyrosine kinase inhibitors) or decreasing effectiveness of DOACs (64-68).

Perioperative anticoagulant therapy. Major surgery for cancer represents an indication of prophylaxis before surgery and for at least 7-10 days after, with extended therapy up to four weeks being considered in abdominal and pelvic high-risk cancer surgery $(20,69-71)$.

Prevention of VTE with DOACs in patients who are scheduled to surgery represents a bold purpose, given the fact that this treatment improves patient adherence and would decrease VTE monitoring and complications (72-74). Cancer surgery increases the risk of thrombosis, especially in older patients, those with recurrent VTE, or prolonged immobilization. Several ongoing trials compare the efficacy and safety of using fondaparinux, LMWH (first and second generation), UFH following major orthopedic and abdominal cancer surgery [NCT01444612 (75), NCT00219973 - bemiparin (76)] and even DOACs [NCT02366871-apixaban (77)].

Brain-tumor patients. The VTE risk in patients with brain tumors is increased up to $60 \%$, after surgery, with an incidence of $20-30 \%$ per year of survival (78-80). Although thromboprophylaxis is necessary, its use is still controversial, due to increased risk of intracranial hemorrhage demonstrated in some studies (81-83).

Patients with increased bleeding risk. Chemotherapy-induced thrombocytopenia increases the risk of bleeding events. The anticoagulant treatment decision is problematic, due to lack of evidence, mainly because of the exclusion of this category of patients from clinical trials. Bleeding risk was assessed in patients with thrombocytopenia who continued to receive lower doses of enoxaparin in case series and a small retrospective study, with promising results $(84,85)$.

\section{Future treatments}

Isoquercetin, a flavonoid that targets endothelial-produced protein disulfite isomerase, thus preventing platelet aggregation, fibrin addition and platelet-dependent thrombin 
generation via blocking of platelet factor Va $(86,87)$, could represent a viable option to prevent VTE in metastatic cancer, such as unresectable or metastatic pancreatic adenocarcinoma, stage III or IV non-small cell lung cancer unresectable, or stage IV colorectal cancer (NCT02195232, CAT IQ, N=618). In this study, the administration of isoquercetin $500 \mathrm{mg}$ and $1000 \mathrm{mg}$ for 56 days, with vascular ultrasound screening, led to an important decrease in platelet-dependent thrombin production, decreased plasmatic D-dimer concentration by a median of $-21.9 \%$ $(\mathrm{P}=0.0002)$, without primary VTE events or major bleeding events observed $(88,89)$. Statins are also investigated for the potential prophylactic effect on VTE, especially in high-risk cancer patients who receive chemotherapy (NCT01524653, DISOLVE) (90).

\section{Conclusions}

Direct anticoagulants could represent a more appealing alternative to low-molecular-weight heparin in paraneoplastic VTE, due to patient comfort, easy administration of the drug and emerging studies that prove similar efficacy and safety as the standard treatment. The increasing number of clinical trials that aim to prove this point is the result of shifting to the need to recommend a simpler, safer and efficient treatment for patients with active cancer or during chemotherapy.

\section{Acknowledgements}

Not applicable.

\section{Funding}

No funding was received.

\section{Availability of data and materials}

Not applicable.

\section{Authors' contributions}

RAI, OGB, TC and RDM collected, analyzed and interpreted the patient data regarding the venous thromboembolism in patients with cancer. DLDM, CCD, MAG and BS had substantial contribution to the conception of the study and interpretation of data; also, they drafted the manuscript and were major contributors in writing the manuscript. All authors read and approved the final manuscript.

\section{Ethics approval and consent to participate}

Not applicable.

\section{Patient consent for publication}

Not applicable.

\section{Competing interests}

The authors declare that they have no competing interests.

\section{References}

1. Levine M: Treatment of thrombotic disorders in cancer patients. Haemostasis 27 (Suppl 1): 38-43, 1997.

2. Carrier M, Khorana AA, Moretto P, Le Gal G, Karp R and Zwicker JI: Lack of evidence to support thromboprophylaxis in hospitalized medical patients with cancer. Am J Med 127: 82-6.e1, 2014.

3. Moheimani F and Jackson DE: Venous thromboembolism: Classification, risk factors, diagnosis, and management. ISRN Hematol 2011: 124610, 2011.

4. Alikhan R, Cohen AT, Combe S, Samama MM, Desjardins L, Eldor A, Janbon C, Leizorovicz A, Olsson CG and Turpie AG; MEDENOX Study: Risk factors for venous thromboembolism in hospitalized patients with acute medical illness: Analysis of the MEDENOX Study. Arch Intern Med 164: 963-968, 2004

5. van Rooden CJ, Schippers EF, Barge RM, Rosendaal FR, Guiot HF, van der Meer FJ, Meinders AE and Huisman MV: Infectious complications of central venous catheters increase the risk of catheter-related thrombosis in hematology patients: A prospective study. J Clin Oncol 23: 2655-2660, 2005.

6. Kenneth AB: Drug-induced thrombosis in patients with malignancy. UpToDate, 2017. https://www.uptodate.com. Accessed January 7, 2019.

7. O'Connell CL, Boswell WD, Duddalwar V, Caton A, Mark LS, Vigen $\mathrm{C}$ and Liebman HA: Unsuspected pulmonary emboli in cancer patients: Clinical correlates and relevance. J Clin Oncol 24: 4928-4932, 2006.

8. Sørensen HT, Mellemkjaer L, Olsen JH and Baron JA: Prognosis of cancers associated with venous thromboembolism. N Engl J Med 343: 1846-1850, 2000

9. Chew HK, Wun T, Harvey D, Zhou H and White RH: Incidence of venous thromboembolism and its effect on survival among patients with common cancers. Arch Intern Med 166: 458-464, 2006.

10. Gross CP, Galusha DH and Krumholz HM: The impact of venous thromboembolism on risk of death or hemorrhage in older cancer patients. J Gen Intern Med 22: 321-326, 2007.

11. Hultcrantz M, Björkholm M, Dickman PW, Landgren O, Derolf $\AA$ R, Kristinsson SY and Andersson TML: Risk for arterial and venous thrombosis in patients with myeloproliferative neoplasms: A population-based cohort study. Ann Intern Med 168: 317-325, 2018.

12. Elting LS, Escalante CP, Cooksley C, Avritscher EB, Kurtin D, Hamblin L, Khosla SG and Rivera E: Outcomes and cost of deep venous thrombosis among patients with cancer. Arch Intern Med 164: 1653-1661, 2004.

13. Walker AJ, Card TR, West J, Crooks C and Grainge MJ: Incidence of venous thromboembolism in patients with cancer - a cohort study using linked United Kingdom databases. Eur J Cancer 49: 1404-1413, 2013.

14. Stein PD, Beemath A, Meyers FA, Skaf E, Sanchez J and Olson RE: Incidence of venous thromboembolism in patients hospitalized with cancer. Am J Med 119: 60-68, 2006.

15. Khorana AA, Francis CW, Culakova E, Kuderer NM and Lyman GH: Frequency, risk factors, and trends for venous thromboembolism among hospitalized cancer patients. Cancer 110: 2339-2346, 2007.

16. Cohen AT, Katholing A, Rietbrock S, Bamber L and Martinez C: Epidemiology of first and recurrent venous thromboembolism in patients with active cancer. A population-based cohort study. Thromb Haemost 117: 57-65, 2017.

17. Kenneth AB: Pathogenesis of the hypercoagulable state associated with malignancy. UpToDate, 2017. https://www.uptodate. com. Accessed January 9, 2019.

18. van Doormaal FF, Raskob GE, Davidson BL, Decousus H, Gallus A, Lensing AW, Piovella F, Prins MH and Büller HR: Treatment of venous thromboembolism in patients with cancer: Subgroup analysis of the Matisse clinical trials. Thromb Haemost 101: 762-769, 2009.

19. Kearon C,Ak1EA, Ornelas J,Blaivas A,JimenezD, Bounameaux H, Huisman M, King CS, Morris TA, Sood N, et al: Antithrombotic therapy for VTE disease. Chest 149: 315-352, 2016.

20. Lyman GH, Bohlke K, Khorana AA, Kuderer NM, Lee AY, Arcelus JI, Balaban EP, Clarke JM, Flowers CR, Francis CW, et al; American Society of Clinical Oncology: Venous thromboembolism prophylaxis and treatment in patients with cancer: American society of clinical oncology clinical practice guideline update 2014. J Clin Oncol 33: 654-656, 2015. 
21. Francis CW, Kessler CM, Goldhaber SZ, Kovacs MJ, Monreal M, Huisman MV, Bergqvist D, Turpie AG, Ortel TL, Spyropoulos AC, et al: Treatment of venous thromboembolism in cancer patients with dalteparin for up to 12 months: The DALTECAN Study. J Thromb Haemost 13: 1028-1035, 2015.

22. Streiff MB,Holmstrom B,Angelini D, Ashrani A,BockenstedtPL, Chesney C, Fanikos J, Fenninger RB, Fogerty AE, Gao S, et al: NCCN Guidelines insights: Cancer-associated venous thromboembolic disease, Version 2.2018. J Natl Compr Canc Netw 16: 1289-1303, 2018

23. Kahale LA, Hakoum MB, Tsolakian IG, Matar CF, Terrenato I, Sperati F, Barba M, Yosuico VE, Schünemann H and Akl EA: Anticoagulation for the long-term treatment of venous thromboembolism in people with cancer. Cochrane Database Syst Rev 6: CD006650, 2018.

24. Lee AY, Levine MN, Baker RI, Bowden C, Kakkar AK, Prins M Rickles FR, Julian JA, Haley S, Kovacs MJ, et al; Randomized comparison of low-molecular-weight heparin versus oral anticoagulant therapy for the prevention of recurrent venous thromboembolism in patients with cancer (CLOT) Investigators: Low-molecular-weight heparin versus a coumarin for the prevention of recurrent venous thromboembolism in patients with cancer. N Engl J Med 349: 146-153, 2003.

25. Meyer G, Marjanovic Z, Valcke J, Lorcerie B, Gruel Y, Solal-Celigny P, Le Maignan C, Extra JM, Cottu P and Farge D: Comparison of low-molecular-weight heparin and warfarin for the secondary prevention of venous thromboembolism in patients with cancer: A randomized controlled study. Arch Intern Med 162: 1729-1735, 2002

26. Deitcher SR, Kessler CM, Merli G, Rigas JR, Lyons RM and Fareed J; ONCENOX Investigators: Secondary prevention of venous thromboembolic events in patients with active cancer: Enoxaparin alone versus initial enoxaparin followed by warfarin for a 180-day period. Clin Appl Thromb Hemost 12: 389-396, 2006.

27. Lee AYY, Kamphuisen PW, Meyer G, Bauersachs R, Janas MS, Jarner MF and Khorana AA; CATCH Investigators: Tinzaparin vs warfarin for treatment of acute venous thromboembolism in patients with active cancer. A randomized clinical trial. JAMA 314: 677-686, 2015

28. Hull RD, Pineo GF, Brant RF, Mah AF, Burke N, Dear R, Wong T, Cook R, Solymoss S, Poon MC, et al; LITE Trial Investigators: Long-term low-molecular-weight heparin versus usual care in proximal-vein thrombosis patients with cancer. Am J Med 119: 1062-1072, 2006.

29. Harrison L, McGinnis J, Crowther M, Ginsberg J and Hirsh J: Assessment of outpatient treatment of deep-vein thrombosis with low-molecular-weight heparin. Arch Intern Med 158: 2001-2003, 1998.

30. Rose AJ, Sharman JP, Ozonoff A, Henault LE and Hylek EM Effectiveness of warfarin among patients with cancer. J Gen Intern Med 22: 997-1002, 2007.

31. Khorana AA, Noble S, Lee AYY, Soff G, Meyer G, O'Connell C and Carrier M: Role of direct oral anticoagulants in the treatment of cancer-associated venous thromboembolism: Guidance from the SSC of the ISTH. J Thromb Haemost 16: 1891-1894, 2018.

32. Prins $M H$, Lensing AW, Bauersachs $R$, van Bellen $B$ Bounameaux H, Brighton TA, Cohen AT, Davidson BL, Decousus H, Raskob GE, et al; EINSTEIN Investigators: Oral rivaroxaban versus standard therapy for the treatment of symptomatic venous thromboembolism: A pooled analysis of the EINSTEIN-DVT and PE randomized studies. Thromb J 11: 21 , 2013.

33. Schulman S, Goldhaber SZ, Kearon C, Kakkar AK, Schellong S, Eriksson H, Hantel S, Feuring M and Kreuzer J: Treatment with dabigatran or warfarin in patients with venous thromboembolism and cancer. Thromb Haemost 114: 150-157, 2015.

34. Vedovati MC, Germini F, Agnelli G and Becattini C: Direct oral anticoagulants in patients with VTE and cancer: A systematic review and meta-analysis. Chest 147: 475-483, 2015.

35. Agnelli G, Buller HR, Cohen A, Gallus AS, Lee TC, Pak R, Raskob GE, Weitz JI and Yamabe T: Oral apixaban for the treatment of venous thromboembolism in cancer patients: Results from the AMPLIFY trial. J Thromb Haemost 13: 2187-2191, 2015.

36. Prisco D, Tufano A, Cenci C, Pignatelli P, Santilli F, Di Minno G and Perticone F: Position paper of the Italian Society of Internal Medicine (SIMI) on prophylaxis and treatment of venous thromboembolism in patients with cancer. Intern Emerg Med 14: 21-38, 2019.
37. https://clinicaltrials.gov/ct2/show/NCT02744092. Accessed April 20, 2016.

38. https://clinicaltrials.gov/ct2/show/NCT03240120. Accessed August 4, 2017.

39. https://clinicaltrials.gov/ct2/show/NCT03045406. Accessed February 7, 2017.

40. https://clinicaltrials.gov/ct2/show/NCT02581176. Accessed October 20, 2015.

41. Raskob GE, van Es N, Verhamme P, Carrier M, Di Nisio M, Garcia D, Grosso MA, Kakkar AK, Kovacs MJ, Mercuri MF, et al; Hokusai VTE Cancer Investigators: Edoxaban for the treatment of cancer-associated venous thromboembolism. N Engl J Med 378: 615-624, 2018.

42. Young AM, Marshall A, Thirlwall J, Chapman O, Lokare A, Hill C, Hale D, Dunn JA, Lyman GH, Hutchinson C, et al: Comparison of an oral factor Xa inhibitor with low molecular weight heparin in patients with cancer with venous thromboembolism: Results of a randomized trial (SELECT-D). J Clin Oncol 36: 2017-2023, 2018.

43. https://clinicaltrials.gov/ct2/show/NCT03139487. Accessed May 4, 2017.

44. https://clinicaltrials.gov/ct2/show/NCT02746185. Accessed April 21, 2016.

45. https://clinicaltrials.gov/ct2/show/NCT02583191. Accessed October 22, 2015.

46. Hakoum MB, Kahale LA, Tsolakian IG, Matar CF, Yosuico VE, Terrenato I, Sperati F, Barba M, Schünemann H and Akl EA: Anticoagulation for the initial treatment of venous thromboembolism in people with cancer. Cochrane Database Syst Rev 1: CD006649, 2018.

47. Cohen AT, Spiro TE, Büller HR, Haskell L, Hu D, Hull R, Mebazaa A, Merli G, Schellong S, Spyropoulos AC, et al; MAGELLAN Investigators: Rivaroxaban for thromboprophylaxis in acutely ill medical patients. N Engl J Med 368: 513-523, 2013.

48. Akl EA, van Doormaal FF, Barba M, Kamath G, Kim SY, Kuipers S, Middeldorp S, Yosuico V, Dickinson HO and Schünemann HJ: Parenteral anticoagulation may prolong the survival of patients with limited small cell lung cancer: A Cochrane systematic review. J Exp Clin Cancer Res 27: 4, 2008.

49. van Doormaal FF, Di Nisio M, Otten HM, Richel DJ, Prins M and Buller HR: Randomized trial of the effect of the low molecular weight heparin nadroparin on survival in patients with cancer. J Clin Oncol 29: 2071-2076, 2011.

50. Yhim HY, Choi WI, Kim SH, Nam SH, Kim KH, Mun YC, Oh D, Hwang HG, Lee KW, Song EK, et al: Long-term rivaroxaban for the treatment of acute venous thromboembolism in patients with active cancer in a prospective multicenter trial. Blood J 130: $3711,2017$.

51. https://clinicaltrials.gov/ct2/show/NCT03214172. Accessed July 11,2017

52. https://clinicaltrials.gov/ct2/show/NCT02742623. Accessed April 19, 2016

53. https://clinicaltrials.gov/ct2/show/NCT01989845. Accessed November 21, 2013

54. https://clinicaltrials.gov/ct2/show/NCT03692065. Accessed October 2, 2018.

55. https://clinicaltrials.gov/ct2/show/NCT02585713. Accessed October 23, 2015.

56. Trujillo-Santos J, Nieto JA, Tiberio G, Piccioli A, Di Micco P, Prandoni P, Monreal M and Registry RIETE; RIETE Registry: Predicting recurrences or major bleeding in cancer patients with venous thromboembolism. Findings from the RIETE Registry. Thromb Haemost 100: 435-439, 2008.

57. Hutten BA, Prins MH, Gent M, Ginsberg J, Tijssen JG and Büller HR: Incidence of recurrent thromboembolic and bleeding complications among patients with venous thromboembolism in relation to both malignancy and achieved international normalized ratio: A retrospective analysis. J Clin Oncol 18: 3078-3083, 2000.

58. Lyman GH, Khorana AA, Kuderer NM, Lee AY, Arcelus JI, Balaban EP, Clarke JM, Flowers CR, Francis CW, Gates LE, et al; American Society of Clinical Oncology Clinical Practice: Venous thromboembolism prophylaxis and treatment in patients with cancer: American Society of Clinical Oncology clinical practice guideline update. J Clin Oncol 31: 2189-2204, 2013.

59. Agnelli G, George DJ, Kakkar AK, Fisher W, Lassen MR, Mismetti P, Mouret P, Chaudhari U, Lawson F and Turpie AG; SAVE-ONCO Investigators: Semuloparin for thromboprophylaxis in patients receiving chemotherapy for cancer. $\mathrm{N}$ Engl $\mathrm{J}$ Med 366: 601-609, 2012 
60. Maraveyas A, Waters J, Roy R, Fyfe D, Propper D, Lofts F, Sgouros J, Gardiner E, Wedgwood K, Ettelaie C, et al: Gemcitabine versus gemcitabine plus dalteparin thromboprophylaxis in pancreatic cancer. Eur J Cancer 48: 1283-1292, 2012.

61. Agnelli G, Gussoni G, Bianchini C, Verso M, Mandalà M, Cavanna L, Barni S, Labianca R, Buzzi F, Scambia G, et al; PROTECHT Investigators: Nadroparin for the prevention of thromboembolic events in ambulatory patients with metastatic or locally advanced solid cancer receiving chemotherapy: A randomised, placebo-controlled, double-blind study. Lancet Oncol 10: 943-949, 2009.

62. https://clinicaltrials.gov/ct2/show/NCT02048865. Accessed January 29, 2014.

63. https://clinicaltrials.gov/ct2/show/NCT02555878. Accessed September 22, 2015.

64. Walenga JM and Adiguzel C: Drug and dietary interactions of the new and emerging oral anticoagulants. Int J Clin Pract 64: 956-967, 2010.

65. Lohr LK: Drug interactions with newer oral chemotherapy agents. US Pharm 34 (Oncology suppl): 4-8, 2009.

66. Neagu M, Caruntu C, Constantin C, Boda D, Zurac S, Spandidos DA and Tsatsakis AM: Chemically induced skin carcinogenesis: Updates in experimental models (Review). Oncol Rep 35: 2516-2528, 2016.

67. Voiculescu VM, Caruntu C, Solomon I, Lupu M, Ilie MA, Boda D, et al: Squamous cell carcinoma: biomarkers and potential therapeutic targets. Human Skin Cancers-Pathways, Mechanisms, Targets and Treatments. IntechOpen, London pp135-159, 2018

68. Lupu M, Caruntu A, Caruntu C, Papagheorghe LML, Ilie MA, Voiculescu V, Boda D, Constantin C, Tanase C, Sifaki M, et al: Neuroendocrine factors: The missing link in non-melanoma skin cancer (Review). Oncol Rep 38: 1327-1340, 2017.

69. Boda D, Docea AO, Calina D, Ilie MA, Caruntu C, Zurac S, Neagu M, Constantin C, Branisteanu DE, Voiculescu V, et al: Human papilloma virus: Apprehending the link with carcinogenesis and unveiling new research avenues (Review). Int $\mathrm{J}$ Oncol 52: 637-655, 2018.

70. Popescu R, Bratu O, Spinu D, Marcu D, Farcas C, Dinu M and Mischianu D: Neuroendocrine differentiation in prostate cancer - a review. Rom J Mil Med 118: 16-19, 2015

71. Marcu D, Spinu D, Mischianu D, Socea B, Oprea I and Bratu O: Oncological follow-up after radical prostatectomy. Rom J Mil Med 120: 39-42, 2017.

72. Radulescu A, Madan V, Aungurenci A, Bratu O, Farcas C, Dinu M and Mischianu D: Antibiotic resistant urinary tract infections in an urology ward. Rom J Mil Med 118: 20-22, 2015.

73. Spinu D, Bratu O, Popescu R, Marcu D, Radulescu A and Mischianu D: Clostridium difficile-an emerging plague. Rom J Mil Med 118: 12-15, 2015.

74. Socea LI, Visan DC, Barbuceanu SF, Apostol TV, Bratu OG and Bogdan S: The antioxidant activity of some acylhydrazones with dibenzo[a,d][7]annulene moiety. Rev Chim Buchar 69: 795-797, 2018.
75. https://clinicaltrials.gov/ct2/show/NCT01444612. Accessed October 3, 2011.

76. https://clinicaltrials.gov/ct2/show/NCT00219973. Accessed September 22, 2005.

77. https://clinicaltrials.gov/ct2/show/NCT02366871. Accessed February 19, 2015.

78. Perry JR, Julian JA, Laperriere NJ, Geerts W, Agnelli G, Rogers LR, Malkin MG, Sawaya R, Baker R, Falanga A, et al: PRODIGE: A randomized placebo-controlled trial of dalteparin low-molecular-weight heparin thromboprophylaxis in patients with newly diagnosed malignant glioma. J Thromb Haemost 8 : $1959-1965,2010$

79. Solomon I, Voiculescu VM, Caruntu C, Lupu M, Popa A, Ilie MA, Albulescu R, Caruntu A, Tanase C, Constantin C, et al: Neuroendocrine factors and head and neck squamous cell carcinoma: An affair to remember. Dis Markers 2018: 9787831, 2018.

80. Boda D: Cellomics as integrative omics for cancer. Curr Proteomics 10: 237-245, 2013.

81. Marras LC, Geerts WH and Perry JR: The risk of venous thromboembolism is increased throughout the course of malignant glioma: An evidence-based review. Cancer 89: 640-646, 2000.

82. Neagu M, Constantin C, Tanase C and Boda D: Patented biomarker panels in early detection of cancer. Recent Pat Biomark 1: 10-24, 2011.

83. Lupu M, Caruntu A, Caruntu C, Boda D, Moraru L, Voiculescu V and Bastian A: Non-invasive imaging of actinic cheilitis and squamous cell carcinoma of the lip. Mol Clin Oncol 8: 640-646, 2018.

84. Herishanu Y, Misgav M, Kirgner I, Ben-Tal O, Eldor A and Naparstek E: Enoxaparin can be used safely in patients with severe thrombocytopenia due to intensive chemotherapy regimens. Leuk Lymphoma 45: 1407-1411, 2004.

85. Ibrahim RB, Skewes MD and Kuriakose P: 'Sailing in troubled waters': A review of the use of anticoagulation in adult cancer patients with thrombocytopenia. Blood Coagul Fibrinolysis 27: 615-630, 2016.

86. Stopa JD, Neuberg D, Puligandla M, Furie B, Flaumenhaft R and Zwicker JI: Protein disulfide isomerase inhibition blocks thrombin generation in humans by interfering with platelet factor V activation. JCI Insight 2: e89373, 2017.

87. Zwicker JI, Schlechter BL, Stopa JD, Liebman HA, Aggarwal A, Puligandla M, Caughey T, Bauer KA, Kuemmerle N, Wong E, et al; CATIQ Investigators 11: Targeting protein disulfide isomerase with the flavonoid isoquercetin to improve hypercoagulability in advanced cancer. JCI Insight 4: ii, 2019.

88. https://clinicaltrials.gov/ct2/show/NCT02195232. Accessed July $21,2014$.

89. Tica OA, Tica O, Antal L, Hatos A, Popescu MI, Pantea Stoian A, Bratu OG, Gaman MA, Pituru SM and Diaconu CC: Modern oral anticoagulant treatment in patients with atrial fibrillation and heart failure: Insights from the clinical practice. Farmacia 66: 972-976, 2018.

90. https://clinicaltrials.gov/ct2/show/NCT01524653. Accessed February 2, 2012. 